\title{
Potential Toxic Effects of Olanzapine on Metabolic Parameters in de Novo Paranoid Schizophrenic Patients. The Role of Adjunctive Aripeprazole: Clinical and Experimental Study
}

\author{
Hisham Mohammed Al-Sayed1', Wafaa Ibrahim Soliman² \\ ${ }^{1}$ Neuropsychiatric Department, Faculty of Medicine, Benha University, Benha, Egypt \\ ${ }^{2}$ Department of Forensic Medicine and Clinical Toxicology, Faculty of Medicine, Zagazig University, Zagazig, Egypt \\ Email: sery1968@yahoo.com,princessmenna2005@yahoo.com
}

How to cite this paper: Al-Sayed, H.M. and Soliman, W.I. (2019) Potential Toxic Effects of Olanzapine on Metabolic Parameters in de Novo Paranoid Schizophrenic Patients. The Role of Adjunctive Aripeprazole: Clinical and Experimental Study. Occupational Diseases and Environmental Medicine, 7, 91-113.

https://doi.org/10.4236/odem.2019.73008

Received: June 3, 2019

Accepted: August 18, 2019

Published: August 21, 2019

Copyright $\odot 2019$ by author(s) and Scientific Research Publishing Inc. This work is licensed under the Creative Commons Attribution International License (CC BY 4.0).

http://creativecommons.org/licenses/by/4.0/

\begin{abstract}
Background: Approximately $75 \%$ of all deaths in people with schizophrenia are caused by physical illness with cardiovascular disease [CVD] being the commonest cause of death. Factors predisposing people with schizophrenia to CVD include antipsychotic medication. Aim of Work: The aim of this study was to detect metabolic syndrome and its components in de novo paranoid schizophrenics on olanzapine therapy and the metabolic benefits of addition of aripeprazole, clinically and experimentally. Methodology: 1) Clinical study: 200 Outpatients suffered from de novo paranoid schizophrenia according to $10^{\text {th }}$ International Classification of Psychiatric Disorders, Research Criteria [ICD10 RC] were included in the study. None of them had any component of metabolic syndrome. They were maintained on olanzapine [10 - $20 \mathrm{mg}$ ]. Patients were assessed clinically, psychometrically using Scale for the Assessment of Negative [SANS] and Positive [SAPS] Symptoms and metabolically at base line and after 6 months. Patients who had metabolic syndrome after 6 month of starting olanzapine therapy, were randomly divided into two groups according to added regime to maintained olanzapine: Group 1: olanzapine [10 mg/day] + placebo [empty hard gelatin capsule]. Group II: olanzapine $[10 \mathrm{mg} /$ day $]+$ aripeprazole $[10 \mathrm{mg} /$ day]. 2) Experimental study: 40 male albino rats were randomly equally divided into 4 groups: Group 1 [control group]: received a standard diet, Group II [olanzapine treated]: received olanzapine at a dose of $0.5 \mathrm{mg} / \mathrm{kg} /$ day, Group III [aripiprazole treatd]: received aripiprazole at a dose of $2 \mathrm{mg} / \mathrm{kg} /$ day, Group IV [combined olanzapine and aripiprazole treated]: received olanzapine at a dose of $0.5 \mathrm{mg} / \mathrm{kg} /$ day combined with aripiprazole at a dose of $2 \mathrm{mg} / \mathrm{kg} /$ day orally. The duration of
\end{abstract}


the study was 16 weeks. All treated rat groups were assessed for metabolic parameters, liver enzymes and histopathology. Results: Clinically, after the 6 months of olanzapine treatment [mean dose $12.75 \mathrm{mg}$ ], there was significant increase $[\mathrm{p}<0.001]$ in weight, body mass index, triglyceride, total cholesterol, and fasting blood glucose level compared to base line level of these parameters (Table 1). 32 patients [16\%] suffered from metabolic syndrome after 6 months of olanzapine therapy. After 3 months of aripeprazole, [10 $\mathrm{mg} /$ day], addition to maintained olanzapine therapy to patients suffered from metabolic syndrome, there was significant $[\mathrm{p}<0.001]$ improvement in tested parameters (Table 2). Experimentally, the rats in group II [olanzapine treated rats] had significantly higher body weight [p $=0.002]$, liver weight [ $<<$ $0.001]$, metabolic parameters $[p<0.001]$ and liver enzymes $[p<0.001]$ than controls. Group 1v [combined olanzapine and aripeprazole treated rats] had significant decrease in metabolic parameters and liver enzymes in comparison to olanzapine treated rats (Table 3). Histopathologically, liver fat cells were significantly $[\mathrm{p}<0.001$ ] present in the olanzapine-only [8 rats] treatment group compared to group $1 \mathrm{v}$ [ 3 rats] and group 11 [zero]. Liver fat cells were higher in number and larger in size in group 1 compared to group $1 \mathrm{v}$ and group 1. Conclusion and Recommendation: Olanzapine treatment was found to be associated with risk factors of metabolic syndrome clinically and experimentally and its hepatic manifestation of non-alcoholic fatty liver disease in wister rats. Improvements were observed clinically and experimentally in metabolic measures, liver enzymes and liver histopathology by addition of aripeprazole. Patients on olanzapine therapy must be followed regularly regarding metabolic parameters, hepatic, cardiac and cerebrovascular morbidity, with urgent interference with early manifestations. It is recommended to check liver enzymes regularly for those patients kept on atypical antipsychotic drug [olanzapine].

\section{Keywords}

Olanzapine, Aripeprazole, Paranoid Schizophrenia, Metabolic Syndrome, Fatty Liver Disease

\section{Introduction}

Schizophrenia is a psychotic illness that affects approximately $1 \%$ of the population. Mortality rates are increased two- to four-fold in people with schizophrenia and life expectancy is reduced by 10 - 20 years [1] [2] [3]. Approximately $75 \%$ of all deaths in people with schizophrenia are caused by physical illness with cardiovascular disease being the commonest cause of death [1].

Since their introduction in 1990, atypical antipsychotics [AAPs] have become the most common treatment for patients with a variety of psychotic disorders [4]. Atypical antipsychotics used for the treatment of schizophrenia offer significant advantages over conventional compounds, particularly because they are 
Table 1. Some metabolic parameters in studied patients at baseline and after six month of olanzapine therapy using Paired t test.

\begin{tabular}{ccccc}
\hline & $\begin{array}{c}\text { Baseline [200] } \\
\text { Mean } \pm \text { SD }\end{array}$ & $\begin{array}{c}\text { After } 6 \mathrm{~m}[200] \\
\text { Mean } \pm \text { SD }\end{array}$ & Paired t test & P value \\
\hline Wt $[\mathrm{kg}]$ & $64.84 \pm 15.8$ & $71.09 \pm 12.96$ & 10.51 & $<0.001^{\star *}$ \\
Wc [cm] & $82.54 \pm 8.84$ & $86.35 \pm 8.28$ & 5.48 & $<0.001^{\star *}$ \\
BMI & $24.46 \pm 10.59$ & $24.71 \pm 10.52$ & 3.23 & $<0.001^{\star *}$ \\
FBG & $84.28 \pm 7.95$ & $90.73 \pm 13.09$ & 6.08 & $<0.001^{\star *}$ \\
TG level & $136.54 \pm 35.09$ & $152.54 \pm 38.16$ & 4.43 & $<0.001^{\star *}$ \\
Total blood Cholesterol & $175.31 \pm 21.48$ & $187.48 \pm 29.74$ & 4.67 & $<0.001^{\star *}$ \\
HDLC & $46.19 \pm 24.41$ & $41.07 \pm 25.42$ & 20.85 & $<0.001^{\star *}$ \\
HbAlc & $5.63 \pm 3.29$ & $5.71 \pm 3.35$ & 7.36 & $<0.001^{\star *}$ \\
SBP & $112.43 \pm 25.07$ & $119.91 \pm 23.84$ & 7.27 & $<0.001^{\star *}$ \\
DBP & $77.11 \pm 17.83$ & $81.5 \pm 17.14$ & 13.51 & $<0.001^{\star *}$ \\
\hline
\end{tabular}

SD: Standard deviation; $\mathrm{t}$ test: student $\mathrm{t}$ test; ${ }^{* *}$ : Highly significant $[\mathrm{P}<0.001]$.

Table 2. Placebo versus aripiprazole in metabolic syndrome patients maintained on olanzapine for three months.

\begin{tabular}{|c|c|c|c|c|}
\hline & $\begin{array}{c}\text { Olanzapine }+ \\
\text { placebo } \\
(\text { number }=16)\end{array}$ & $\begin{array}{l}\text { Olanzapine+ } \\
\text { aripiprazole } \\
\text { (number }=16 \text { ) }\end{array}$ & St t test & $\mathrm{P}$ \\
\hline \multicolumn{5}{|l|}{ Weight $[\mathrm{kg}]$} \\
\hline $0 \mathrm{~m}$ & $78.86 \pm 3.44$ & $77.47 \pm 2.79$ & 1.26 & 0.22 \\
\hline $3 \mathrm{~m}$ & $81.37 \pm 1.71$ & $74.24 \pm 1.38$ & 13.0 & $<0.001^{\star *}$ \\
\hline Paired t test & 2.90 & 3.80 & & \\
\hline $\mathrm{P}$ & $0.011^{\star}$ & $0.002^{\star *}$ & & \\
\hline \multicolumn{5}{|c|}{ Waist circumference $[\mathrm{cm}]$} \\
\hline $0 \mathrm{~m}$ & $91.91 \pm 3.15$ & $90.24 \pm 3.75$ & 1.36 & 0.19 \\
\hline $3 \mathrm{~m}$ & $92.23 \pm 2.39$ & $89.79 \pm 1.10$ & 3.71 & $0.001^{\star *}$ \\
\hline Paired t test & 0.43 & 0.52 & & \\
\hline $\mathrm{P}$ & 0.67 & 0.61 & & \\
\hline \multicolumn{5}{|l|}{ BMI } \\
\hline $0 \mathrm{~m}$ & $24.83 \pm 2.36$ & $24.88 \pm 2.12$ & 0.07 & 0.94 \\
\hline $3 \mathrm{~m}$ & $24.92 \pm 2.35$ & $24.74 \pm 2.13$ & 0.22 & 0.83 \\
\hline Paired $t$ test & 0.36 & 0.93 & & \\
\hline $\mathrm{P}$ & 0.72 & 0.37 & & \\
\hline
\end{tabular}




\section{Continued}

Fasting blood glucose

$\begin{array}{ccccc}0 \mathrm{~m} & 112.08 \pm 2.05 & 111.89 \pm 2.10 & 0.25 & 0.81 \\ 3 \mathrm{~m} & 112.04 \pm 2.02 & 104.73 \pm 7.93 & 3.58 & 0.001^{* *} \\ \text { Paired t test } & 2.42 & 3.17 & & \\ \mathrm{P} & 0.029^{*} & 0.006^{* *} & & \end{array}$

Serum Triglyceride

$\begin{array}{ccccc}0 \mathrm{~m} & 168.94 \pm 4.33 & 167.56 \pm 3.41 & 1.0 & 0.33 \\ 3 \mathrm{~m} & 182.31 \pm 11.59 & 145.25 \pm 8.08 & 10.49 & <0.001^{* *}\end{array}$

Paired t test

P

4.91

11.03

$<0.001^{* *}<0.001^{* *}$

Total blood Cholesterol

$3 \mathrm{~m}$

Paired t test

P

HDLC

\begin{tabular}{|c|c|c|c|c|}
\hline $0 \mathrm{~m}$ & $37.94 \pm 2.84$ & $38.09 \pm 6.32$ & 0.087 & 0.93 \\
\hline $3 \mathrm{~m}$ & $37.13 \pm 2.45$ & $38.34 \pm 6.15$ & 0.73 & 0.47 \\
\hline Paired $t$ test & 1.98 & 1.29 & & \\
\hline$P$ & 0.066 & 0.22 & & \\
\hline \multicolumn{5}{|l|}{$\mathrm{Hb}_{\mathrm{Alc}}$} \\
\hline $0 \mathrm{~m}$ & $5.85 \pm 0.63$ & $5.79 \pm 0.62$ & 0.26 & 0.80 \\
\hline $3 \mathrm{~m}$ & $5.92 \pm 0.66$ & $5.81 \pm 0.58$ & 0.52 & 0.61 \\
\hline Paired $t$ test & 1.74 & 0.31 & & \\
\hline$P$ & 0.10 & 0.76 & & \\
\hline \multicolumn{5}{|l|}{ SBP } \\
\hline $0 \mathrm{~m}$ & $123.88 \pm 3.91$ & $123.54 \pm 3.74$ & 0.25 & 0.81 \\
\hline $3 \mathrm{~m}$ & $126.02 \pm 3.24$ & $122.8 \pm 3.44$ & 2.73 & $0.011^{*}$ \\
\hline Paired $t$ test & 1.70 & 2.16 & & \\
\hline $\mathrm{P}$ & 0.11 & $0.047^{\star}$ & & \\
\hline \multicolumn{5}{|l|}{ DBP } \\
\hline $0 \mathrm{~m}$ & $82.23 \pm 1.83$ & $81.78 \pm 2.04$ & 0.67 & 0.51 \\
\hline $3 \mathrm{~m}$ & $84.36 \pm 3.48$ & $80.76 \pm 2.40$ & 3.4 & $0.002^{* *}$ \\
\hline Paired $t$ test & 2.09 & 1.35 & & \\
\hline $\mathrm{P}$ & 0.054 & 0.20 & & \\
\hline
\end{tabular}

$\mathrm{SD}$ : Standard deviation ${ }^{*}$ : Highly significant $[\mathrm{P}<0.001]$; t test: student $\mathrm{t}$ test ${ }^{*}$ : significant $[\mathrm{P}<0.05]$. 
Table 3. Metabolic parameters and liver function tests in rats of different studied groups using ANOVA test.

\begin{tabular}{|c|c|c|c|c|c|c|}
\hline & $\begin{array}{c}\text { Control group }[10] \\
\text { Mean } \pm \text { SD }\end{array}$ & $\begin{array}{l}\text { Group } 2[10] \\
\text { olanzapine } \\
\text { Mean } \pm \text { SD }\end{array}$ & $\begin{array}{l}\text { Group } 3[10] \\
\text { aripeprazole } \\
\text { Mean } \pm \text { SD }\end{array}$ & $\begin{array}{c}\text { Group } 4[10] \\
\text { Olanzapine +aripeprazole } \\
\text { Mean } \pm \text { SD }\end{array}$ & F test & $\mathrm{P}$ value \\
\hline Baseline wt $[\mathrm{gm}]$ & $179.5 \pm 14.81$ & $182.5 \pm 20.17$ & $181.2 \pm 13.29$ & $177.9 \pm 17.79$ & 0.15 & 0.93 \\
\hline Wt at End of study [gm] & $247.2 \pm 28.92$ & $288.1 \pm 51.05 \$$ & $221.4 \pm 20.9^{\wedge}$ & $253.3 \pm 36.62^{\wedge}$ & 5.78 & $0.002^{\star *}$ \\
\hline Liver wt $[\mathrm{gm}]$ & $12.095 \pm 0.23$ & $13.76 \pm 0.45 \$$ & $12.22 \pm 0.15^{\wedge}$ & $13.01 \pm 0.38 \$ \wedge €$ & 55.87 & $<0.001^{\star *}$ \\
\hline total Cholesterol & $54.8 \pm 20.71$ & $77.68 \pm 21.5 \$$ & $50.91 \pm 22.15^{\wedge}$ & $62.8 \pm 4.59$ & 4.0 & $0.015^{\star}$ \\
\hline FBS & $124.97 \pm 5.25$ & $141.4 \pm 10.11 \$$ & $126.0 \pm 7.67 \wedge$ & $129.7 \pm 8.58^{\wedge}$ & 8.66 & $<0.001^{* *}$ \\
\hline Triglycerides & $130.0 \pm 8.19$ & $215.4 \pm 13.43 \$$ & $133.1 \pm 11.17^{\wedge}$ & $171.2 \pm 16.92 \$ \wedge €$ & 97.08 & $<0.001^{* *}$ \\
\hline ALT & $24.32 \pm 1.26$ & $67.3 \pm 1.63 \$$ & $27.46 \pm 1.72 \$ \wedge$ & $58.23 \pm 1.1 \$ \wedge €$ & 2230.0 & $<0.001^{\star *}$ \\
\hline AST & $51.59 \pm 1.42$ & $89.64 \pm 1.73 \$$ & $54.64 \pm 1.43 \$ \wedge$ & $73.41 \pm 1.57 \$ \wedge €$ & 1319.8 & $<0.001^{\star *}$ \\
\hline AlP & $71.73 \pm 1.24$ & $79.07 \pm 1.37 \$$ & $74.22 \pm 0.90 \$ \wedge$ & $76.55 \pm 1.47 \$ \wedge €$ & 61.88 & $<0.001^{\star *}$ \\
\hline Bilirubin & $0.49 \pm 0.03$ & $0.81 \pm 0.08 \$$ & $0.57 \pm 0.14^{\wedge}$ & $0.64 \pm 0.13 \$ \wedge$ & 16.88 & $<0.001^{\star *}$ \\
\hline
\end{tabular}

$\$$ : significant \& control group SD: Standard deviation; ^: significant \& group $2 \mathrm{t}$ test: student $\mathrm{t}$ test; $€$ : significant \& group $3{ }^{* *}$ : Highly significant [P $<0.001$ ]; *: significant $[\mathrm{P}<0.05]$. 
Non-Alcoholic fatty liver disease [NAFLD], is considered the hepatic manifestation of metabolic syndrome [MetS] [20]. NAFLD is common and has a spectrum of liver changes beginning with simple fatty liver and progressing to steatohepatitis, cirrhosis and liver failure. Alcoholic fatty liver disease [AFLD] is frequently present along with the components of metabolic syndrome and, hence, is generally regarded as a manifestation of metabolic syndrome [21]. Non-alcoholic steatohepatitis [NASH] is recognized as a progressive form of fatty liver disease, has been documented to have the potential to progress to cirrhosis and hepatocellular carcinoma [21] [22].

The aim of this study was to detect MetS and its components in people with de novo paranoid schizophrenia on olanzapine therapy. We aimed to assess the safety and the metabolic benefits of addition of aripeprazole to olanzapine treated patients suffered from metabolic syndrome. Experimentally, we aimed to investigate the metabolic effect of olanzapine and its hepatic effects in wister rats and the effect of adjunctive aripeprazole.

\section{Subject and Method}

\section{Drugs}

- Olanzapine 5, $10 \mathrm{mg}$ tablet [Zyprexa] obtained from Eli Lilly pharmaceutical company.

- Aripeprazole $10 \mathrm{mg}$ tablet [Aripeprex] obtained from Al Andalous pharmaceutical company.

\subsection{Clinical Study}

Subjects were recruited from neuro-psychiatric outpatient of Benha University hospital and Benha psychiatric hospital from $1^{\text {st }}$ of January to $30^{\text {th }}$ of December 2018. The study was approved by the ethical committee of Benha University.

200 Outpatients suffered from de novo paranoid schizophrenia according to ICD10 RC [23] were included in the study after providing written informed consent.

\section{Exclusion criteria:}

- Patients with any component of metabolic syndrome. They were diagnosed according to the recommendation of the International Diabetes Federation [IDF] Task Force on Epidemiology and Prevention [joint interim statement in 2009] [19],

- Substance abuse,

- Pregnant and lactating mothers,

- Any co-morbid medical, neurological and psychiatric illness

At base line [0 month], and 6 months, all of the following parameters were performed:

- Diagnostic evaluation by two different psychiatric consultants.

- Symptom rating scales using Scale for the Assessment of Negative [SANS] [24] and Positive [SAPS] Symptoms [25]. 
- Medical history and examination.

- Weight $[\mathrm{Wt}][\mathrm{kg}]$, height $[\mathrm{cm}]$, body mass index [BMI], and waist circumference [suprailiac] $[\mathrm{wc}][\mathrm{cm}]$.

- Laboratory examination for fasting blood glucose [FBG], glycosylated hemoglobin [HbA1c], total blood cholesterol, triglyceride level [TG], and high density lipo-protein cholesterol [HDL C].

Fasting serum glucose $[\mathrm{mg} / \mathrm{dl}]$ was determined colorimetrically using a test reagent kit [Biolabo SA, France] according to manufacturer's method.

Glycosylated hemoglobin was estimated by a commercial kit [BioSystem SA, Barcelona, Spain] according to manufacturer's method.

Total blood cholesterol, serum triglyceride [TG] and HDL were estimated using test reagent kits [Spinreact, Spain] and expressed as $\mathrm{mg} / \mathrm{dl}$ according to manufacturer's method.

All subjects were maintained on olanzapine [10 - $20 \mathrm{mg}$ ]. Patients had to be maintained on stable dose of olanzapine for at least 3 months. All patients had psycho-education program and their care givers concerning appropriate diet and physical activity for the patients.

Patients who had metabolic syndrome after 6 months of starting olanzapine therapy were randomly divided into two groups according to added regime to maintained olanzapine:

Group I: Olanzapine [10 mg/day] + placebo [prepared starch tablet similar in shape to aripiprazole tablet]

Group II: Olanzapine [10 mg/day] +aripiprazole [10 mg/day]

After three months, the two groups were subjected to assessment of all previous parameters.

\subsection{Experimental Study}

\subsubsection{Ethical Consideration of Study}

The experimental procedures and the use of laboratory animal were approved by the Animal Research Committee in Zagazig University. Painless procedures were conducted. Animal housing and handling were ethically considered.

\subsubsection{Animals}

The current study was performed using 40 albino rats [male, 150 - 180 g, 12 - 16 weeks-old] obtained from the Faculty of Veterinary Medicine, Zagazig University. Rats were housed in stainless steel cages and maintained under standardized environmental conditions $\left[25^{\circ} \mathrm{C}\right]$ away from any stress with a 12 -hr light/dark cycle and 50\% humidity.

All rats had ad libitum access to standard rodent chow and filtered water. Rats were acclimatized for 1 week before use in the experiments.

Animals were randomly equally divided into 4 groups:

Group I [control group]: received a standard diet, for 16 weeks

Group II [olanzapine treated]: received olanzapine at a dose of $0.5 \mathrm{mg} / \mathrm{kg} / \mathrm{day}$, according to the drug calculation formula [26] [27] [28]. Each tablet [5 mg], was 
dissolved in $10 \mathrm{ml}$ normal saline, and each rat received $1 \mathrm{ml} / \mathrm{kg} /$ day of the dissolved drug via gastric tube to ensure that no drug loss occurs [29] [30].

Group III [aripiprazole treatd]: received aripiprazole at a dose of $2 \mathrm{mg} / \mathrm{kg} / \mathrm{day}$, according to the drug calculation formula [26] [27] [28]. Each tablet [10 mg], was dissolved in $10 \mathrm{ml}$ normal saline, and each rat received $2 \mathrm{ml} / \mathrm{kg} /$ day of the dissolved drug via gastric tube [31].

Group IV [combined olanzapine and aripiprazole treated]: received olanzapine at a dose of $0.5 \mathrm{mg} / \mathrm{kg} / \mathrm{day}$ combined with aripiprazole at a dose of 2 $\mathrm{mg} / \mathrm{kg} /$ day by gastric tube daily for 16 weeks.

The duration of the study was 16 weeks. Male rats were selected to obviate potential interactions with ovarian hormones previously found to influence primary outcome measures [32] [33].

Body weight was recorded once weekly. By the end of the treatment period, animals were then fasted for $12 \mathrm{~h}$ and blood samples were withdrawn from the retro-orbital plexus for the Assessment of metabolic and biochemical parameters. Then all animals were scarified under light ether anathesia. The liver of each rat was removed and weighed then stained for histopathological studies.

\subsubsection{Assessment of Metabolic and Biochemical Parameters}

- Fasting serum glucose $[\mathrm{mg} / \mathrm{dl}]$ was determined colorimetrically using a test reagent kit [Biolabo SA, France]

- Total blood cholesterol and serum triglyceride [TG] were estimated using test reagent kits [Spinreact, Spain] and expressed as $\mathrm{mg} / \mathrm{dl}$

- Determination of serum bilirubin and some liver enzymes: Alanine aminotransferase [ALT], Aspartate aminotransferase [AST], and alkaline phosphatase [ALP] using a kit supplied by Human, Germany, according to the instructions of the supplier.

\subsubsection{Histopathological Examinations}

- Liver slides for histopathological study were prepared and stained with routine hematoxylin and eosin staining [34].

\subsection{Statistical Analysis}

Data were expressed as mean \pm standard error of mean. Comparison between the mean values of different groups was carried out using one-way analysis of variance, Data were analyzed by Statistical Package of Social Science [SPSS], software version 22.0 [35].

The $P<0.05$ was considered to indicate statistical significance between groups.

\section{Results}

\subsection{Clinical Results}

After 6 months of olanzapine treatment [mean dose $12.75 \mathrm{mg}$ ], there was significant increase in weight $[\mathrm{Wt}]$, waist circumference [wc], body mass index [BMI], 
triglyceride [TG], total cholesterol, fasting blood glucose level [FBG], glycosylated hemoglobin $[\mathrm{HbA1C}]$, systolic blood pressure [SBP] and diastolic blood pressure [DBP] compared to base line level of these parameters. There was a significant decrease in high-density lipoprotein cholesterol [HDLC] compared to base line level.

32 patients [16\%] suffered from metabolic syndrome after 6 months of olanzapine therapy.

After 3 months of aripiprazole, [10 mg/day], addition to maintained olanzapine therapy to patients suffered from metabolic syndrome, there was significant decrease in body weight, waist circumference, triglyceride, total cholesterol, and fasting blood glucose level compared to placebo control group [maintained on olanzapine therapy].

Aripeprazole treatment did not significantly changed [SANS] [12.6 \pm 1.01$]$ and [SAPS] [10.03 \pm 1.34$]$ score. Akasthisia in some cases managed by short period of small dose of benzodiazepine.

\subsection{Experimental Results}

\section{Body Weight and Liver Weight}

After 16 weeks, The rats in group II [olanzapine treated rats] had significantly higher body weight and liver weight than controls [group I], group III [aripeprazole treated rats] and group IV [combined olanzapine and aripeprazole treated rats] Table 3 . In contrast, the rats in group IV [combined olanzapine and aripeprazole treated rats] had significantly lower body weight and liver weight than those with olanzapine-treated group [group II].

The present study revealed increased level of metabolic parameters [total cholesterol, fasting blood glucose level, triglyceride] and liver enzymes [Alanine aminotransferase [ALT], Aspartate aminotransferase [AST] and alkaline phosphatase [ALP]] in group II [olanzapine treated rats] when compared with other groups.

Histological examination of liver in control group showed the maintenance of normal lobular architecture, normal histology (Figure 1). Histopathological finding in olanzapine treated rat group (Figure 3 ) in the present study showed a picture of non-alcoholic liver disease in the form of ballooning degeneration, inflammatory infiltrates and accumulated lipid vacuoles in hepatocytes [steatosis]. Many Kupffer cells were also present. It had larger total fat cell areas than the control. There was no significant portal inflammation or hepatocytes damage at aripeprazole treated rats (Figure 2). Combined olanzapine- and aripiprazole-treated rats (Figure 4) showed less prominent and less severe picture of non-alcoholic liver disease compared to olanzapine treated rats [the portal tract showed small aggregates of chronic inflammatory cells, fewer Kupffer cells, few fatty changes and ballooning degeneration].

\section{Discussion}

People with severe mental illness [SMI], including schizophrenia and related psychotic disorders, bipolar disorder and major depressive disorder [MDD], 


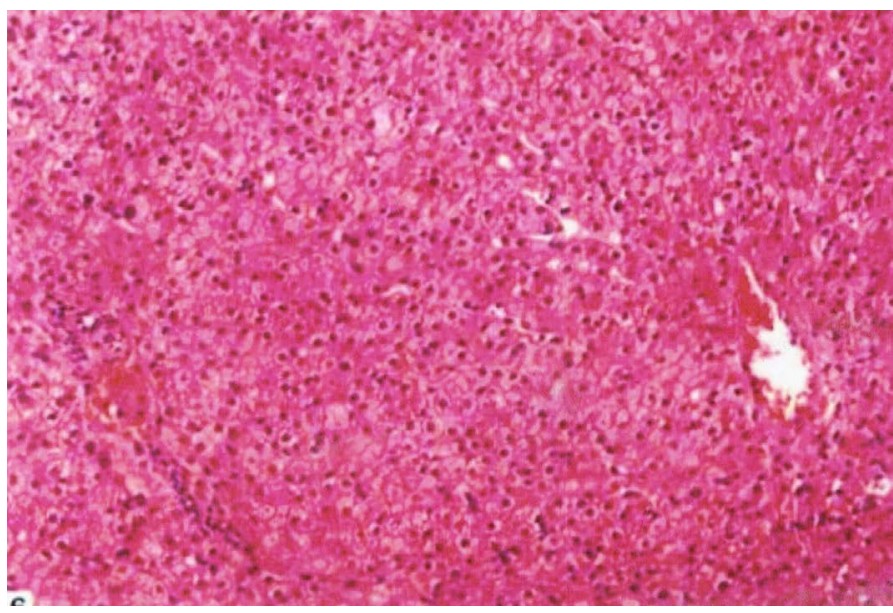

Figure 1. A photomicrograph of hepatic tissue of adult albino rat of control group [received a standard diet, for 16 weeks], showing normal hepatic tissue [H $\times \& \mathrm{E} \times 200]$.

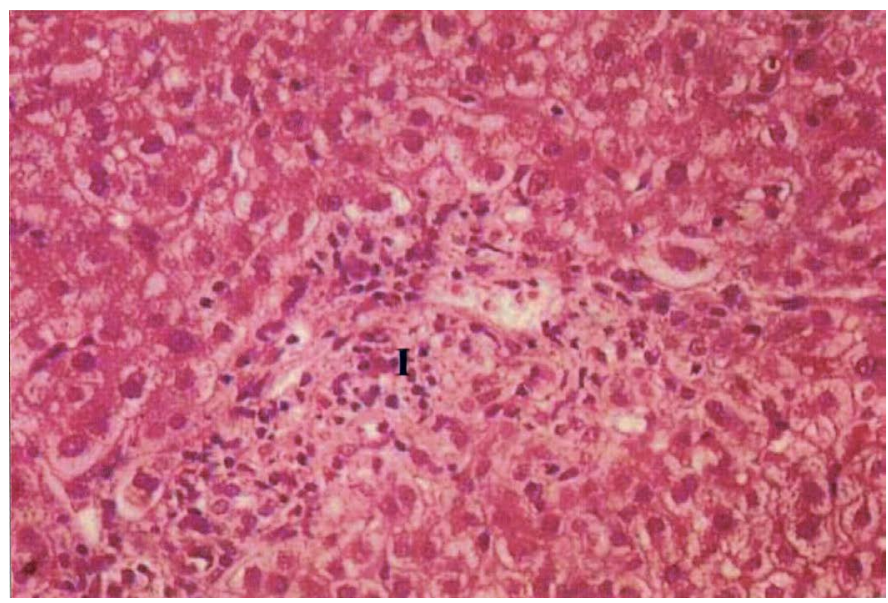

Figure 2. A photomicrograph of hepatic tissue of adult albino rat of aripeprazole group, [at a dose of $2 \mathrm{mg} / \mathrm{kg} /$ day for 16 weeks], showing few inflammatory cells [I] in the portal tract $[\mathrm{H} \times \& \mathrm{E} \times 300]$.

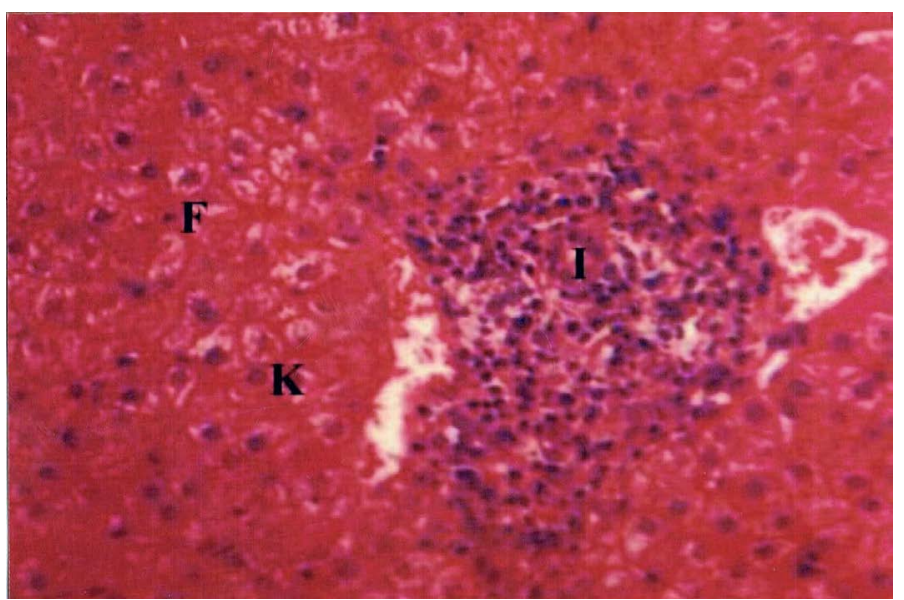

Figure 3. A photomicrograph of hepatic tissue of adult albino rat of olanzapine group [at a dose of $0.5 \mathrm{mg} / \mathrm{kg} /$ day for 16 weeks] showing portal tract infiltration with inflammatory cells [I], hyperplasia of kupffer cell [K] with focal fatty canges [F] $[\mathrm{H} \times \& \mathrm{E} \times 200]$. 


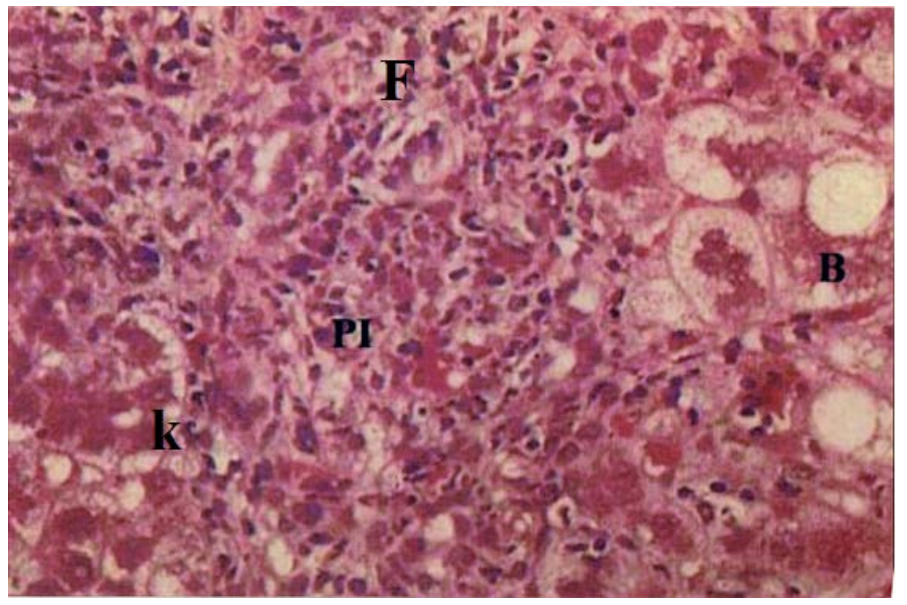

Figure 4. A photomicrograph of liver tissue of adult albino rat of combined aripeprazole [at a dose of $2 \mathrm{mg} / \mathrm{kg} / \mathrm{day}$ for 16 weeks], and olanzapine [at a dose of $0.5 \mathrm{mg} / \mathrm{kg} /$ day for 16 weeks] showing few inflammatory cells [PI] in the portal tract, fewer Kupffer cells [K], few fatty changes $[\mathrm{F}]$ and ballooning degeneration $[\mathrm{B}][\mathrm{H} \times \& \mathrm{E} \times 300]$.

experience a two-three times higher mortality rate than the general population [36] [37]. This mortality gap translates into a 10 - 20-year shortened life expectancy [38] [39] and appears to be widening [40]. About $60 \%$ of the excess mortality observed in SMI is due to physical comorbidities, predominantly cardiovascular diseases [CVD] [41]. Factors predisposing people with SMI to CVD include antipsychotic medication and unhealthy lifestyles [42] as well as their reduced likelihood to receive standard levels of medical care [43] [44] [45].

200 Outpatients suffered from de novo paranoid schizophrenia according to ICD10 RC [23] were included in the study. Few studies have included people with a first episode of psychosis and yet weight gain occurs commonly and rapidly in this group of individuals after treatment initiation. We have also specifically included people with first-episode psychosis, where the aim of the intervention may be the prevention of weight gain rather than weight loss [46].

No Patient had any component of metabolic syndrome. The diagnosis of metabolic syndrome [MetS] was determined based on the recommendation of the International Diabetes Federation Task Force on Epidemiology and Prevention [joint interim statement in 2009] [19]. According to the established definition, metabolic syndrome was identified in persons who met at least 3 out of 5 criteria

1) Waist circumference $\geq 94 \mathrm{~cm}$ in males; $\geq 80 \mathrm{~cm}$ in females- 3

2) Fasting glucose $\geq 100 \mathrm{mg} / \mathrm{dl}[5.5 \mathrm{mmol} / \mathrm{l}]$ or diabetes- 2 treatment

3) Triglycerides $\geq 150 \mathrm{mg} / \mathrm{dL}$ [1.7 mmol/l] or drug treatment-3 for elevated triglycerides

4) $\mathrm{HDL}$ cholesterol $\leq 40 \mathrm{mg} / \mathrm{dL}[1.7 \mathrm{mmol} / \mathrm{l}]$ in males, $\leq 50 \mathrm{mg} / \mathrm{dl}[1.3 \mathrm{mmol} / \mathrm{l}]$ in females.

5) Systolic blood pressure $\geq 130 \mathrm{mmHg}$ or diastolic blood pressure $\geq 85$ $\mathrm{mmHg}$, or drug treatment for hypertension.

36 [15.3\%] paranoid schizophrenic patients were excluded. 15 of them suffered from metabolic syndrome and 10 had one component and 11 had two 
components of metabolic syndrome according to the International Diabetes Federation Task Force on Epidemiology and Prevention [joint interim statement in 2009] [19]. Comparing MetS in first versus multi-episode patients within illness subgroups, first episode psychosis patients [13.7\%] had a significantly lower MetS risk than those with multi-episode schizophrenia [34.2\%]. Although mean age predicted MetS prevalence. First episode was also a unique predictor of lower MetS [47].

Several studies indicated that obesity is two to three times more prevalent among people with schizophrenia than in the general population and this occurs early in its natural history [48].

After the 6 months of olanzapine treatment [mean dose $12.75 \mathrm{mg}$ ], there was significant increase in weight, body mass index, triglyceride, total cholesterol, and fasting blood glucose level compared to base line level of these parameters (Table 1).

Olanzapine treated patients [200 patients] for 6 months demonstrated a main weight gain of $6.25 \mathrm{~kg}$ in this study. Osser et al. [49] found $12 \mathrm{lb}$ [pound] as a main weight gain after 12 weeks of a main olanzapine dose [13.8 mg]. Another study found that, $94 \%$ of day-treatment patients treated with olanzapine [main dose $14.1 \mathrm{mg}$ ] experienced weight gain of greater than $7 \%$ and the main weight gain was $22.1 \mathrm{lb}$ over 7 months [50].

This is in line with many systematic reviews and meta-analyses which reported that olanzapine and clozapine induce most severe weight gain when compared with other antipsychotics [51] [52] [53] [54].

Experimentally, Olanzapine treated rats had significantly more body weight and liver weight compared to other three studied groups, which was corresponding with previous reports [54] [55] [56] [57] [58].

Weight gain is a common adverse effect of antipsychotic medication, affecting between $15 \%$ and $72 \%$ of patients [59] Most weight gain occurs early in treatment. Between $37 \%$ and $86 \%$ of those experiencing a first episode of psychosis also experiencing more than $7 \%$ weight gain in 12 months [60], often occurring within 12 weeks of treatment initiation [61].

In a trial to explain the mechanism of olanzapine-induced weight gain, several animal studies have found that olanzapine could modulate histaminergic neurotransmission for the regulation of food intake and weight gain in rats [62] [63]. Further evidence showed that weight gain and obesity associated with olanzapine are mediated by activation of the hypothalamic AMP-activated protein kinase [AMPK] pathway via blockade of $\mathrm{H}_{1}$ receptors [64] [65], and [66]. In fact, a recent study revealed an association between polymorphisms in the AMPK gene and weight gain induced by olanzapine and clozapine [67]. Additionally, it was reported that olanzapine down-regulates the anorexigenic neuropeptide proopiomelanocortin $[\mathrm{POMC}]$, but up-regulates the orexigenic neuropeptide $\mathrm{Y}$ [NPY], in the arcuate nuclei of the hypothalamus [Arc] [68] [69]

There was significant increase in serum triglyceride level in olanzapine treated patients for 6 months. The main increase was $16 \mathrm{mg} / \mathrm{dl}$. Olanzapine treated rats 
in our study showed significant more triglyceride level than other studied groups. Hypertriglyceridemia has been linked to olanzapine therapy [70] [71]. Atmaca et al. [72] observed a significant increase in weight and triglyceride levels in olanzapine-treated groups. Sheitman et al. [73] reported an increase in serum triglyceride from baseline to 16-month re-assessment where triglycerides increased more than $40 \%$.

There is evidence that AAPs may cause hypertriglyceridemia through several possible mechanisms: 1) a direct effect on triglyceride metabolism either by stimulation of hepatic triglyceride production and secretion or by inhibition of lipoprotein lipase-mediated triglyceride hydrolysis and 2) an indirect mechanism associated with obesity and insulin resistance [74].

Olanzapine treated patients for 6 months demonstrated a main increase in fasting blood glucose [6.35 mg], cholesterol level [12.17 mg] and decrease in HDLC [5.12 mg]. Olanzapine treated rats in our study showed significant more fasting blood glucose, cholesterol level than other studied groups. Abnormalities of triglyceride and HDL metabolism are an early manifestation of insulin resistance, often detectable even before the development of abnormal postprandial or fasting glucose levels [75].

It has been found that the metabolic disturbances associated with the use of atypical antipsychotics are a direct consequence of alteration of insulin sensitivity. Impaired parasympathetic regulation of $\beta$-cell activity mediated by blockade of histaminergic and muscarinic receptors may contribute to an increased metabolic risk [76].

32 patients [16\%] suffered from metabolic syndrome after 6 months of olanzapine therapy according to the recommendation of the International Diabetes Federation [IDF, 2009] Task Force on Epidemiology and Prevention [19]. MetS risk was significantly higher with clozapine, followed by olanzapine. [44] [77].

Olanzapine, can induce metabolic disturbances, such as obesity, hypertriglyceridemia, glucose dysregulation, and in some studies, elevated serum cholesterol levels [78] [79]. These metabolic disturbances may lead to an increase in the risk of cardiovascular diseases and premature mortality [8]. Despite these problems, the use of metabolically potent antipsychotic drugs is widespread, arguably due to superior therapeutic efficacy compared with antipsychotics with more favorable metabolic profiles [80].

While switching to a more weight-neutral atypical antipsychotic agent offers promise in halting or reversing weight gain, many patients and their clinicians are reluctant to risk a worsening or return of psychotic symptoms and risk relapse [81].

Experimentally, there was no significant difference between aripiprazole [ARI] treated group and control group as regards to metabolic changes in rats.

This is in accordance with Greenaway and Elbe.'s review study [82], in which they discussed 4 prospective randomized controlled trials and 9 open-label prospective studies about aripiprazole. They found that in all 4 randomized controlled trials, there was no significant increase in body weight. 
ARI is associated with a lower risk of metabolic and cardiac issues such as weight gain, diabetes, and dyslipidemia than most SGAs [83]. Also, Sayyaparaju et al. [84] stated that aripiprazole was associated with minimal weight gain and metabolic changes [dyslipidemia, elevated serum triglycerides and impairments in glycemic control] unlike most second -generation antipsychotics.

The lowest MetS prevalence for aripiprazole is noteworthy, as antipsychotics with lower cardiometabolic risk profiles in short-term studies are often prescribed for higher risk patients in clinical care, which may lead to a not reduced or even increased cardiometabolic risk in naturalistic settings [85].

After 3 months of aripiprazole, [10 $\mathrm{mg} /$ day], addition to maintained olanzapine therapy to patients suffered from metabolic syndrome, there was significant decrease in body weight, triglyceride, total cholesterol, and fasting blood glucose level compared to placebo-controlled group [maintained on olanzapine therapy]. Aripeprazole treatment did not significantly changed [SANS] [12.6 \pm 1.01 ] and [SAPS] [10.03 \pm 1.34$]$ score. Combined olanzapine and aripiprazole treated rat group showed significant decrease in, body weight, liver weight, fasting blood Glucose, triglyceride, and cholesterol level when compared to olanzapine treated rats (Table 3 ).

Combined olanzapine and aripiprazole treated group showed significant decrease in body weight when compared to olanzapine treated group. Similar results were found by Henderson et al. [86], who report the results of a 10-week placebo controlled, double-blind crossover study that examined $15 \mathrm{mg} /$ day aripiprazole's effects upon multiple parameters including weight in overweight and obese schizophrenia and schizoaffective disorder subjects treated with a stable dose of olanzapine. They found that, subjects experienced significant reductions in weight after the addition of aripiprazole to a stable dose of olanzapine. And that aripiprazole was well tolerated.

Combined olanzapine and aripiprazole treated rat group showed significant decrease in, liver enzymes and serum bilirubin level when compared to olanzapine treated rats (Table 3). Olanzapine treated rats had more significant increase in liver enzymes and serum bilirubin level when compared to control group and aripeprazole treated rats. This is in line with Gonzalez et al. [87] and Ozcanli et al. [88]. Atypical antipsychotic drugs commonly cause asymptomatic increase in the liver enzymes and serum bilirubin levels, but rarely cause serious hepatotoxicity [89]. There exists a single study on olanzapine-induced hepatotoxicity supplemented with the histopathological findings that reported no damage to the general architecture of liver except to hepatocytes at cellular level, using doses of 2 and $4 \mathrm{mg} / \mathrm{kg} / \mathrm{d}$ i.p for six weeks [90]. Liver enzymes elevation has been, however, reported extensively, but asymptomatic and returned to normal when the drug was discontinued [87] [88]. On the other hand, Gomez and colleagues studied more than 2000 patients treated with olanzapine who exhibited no symptoms of jaundice or clinical hepatitis at six month follow-up [10].

The association of Non-Alcoholic fatty liver disease [NAFLD], and metabolic syndrome [MetS] has been previously reported [91]. 
The importance of linking olanzapine, metabolic syndrome and liver steatosis came from the recent finding of Ballestri et al. [20] that, NAFLD is considered the hepatic manifestation of metabolic syndrome [MetS].

Histological examination of liver in control group (Figure 1) shows the maintenance of normal lobular architecture, normal histology. Histopathological finding in olanzapine treated rat group (Figure 3) in the present study showed a picture of non-alcoholic liver disease in the form of ballooning degeneration, inflammatory infiltrates and accumulated lipid vacuoles in hepatocytes [steatosis] [8 rats]. Steatosis was predominantly microvesicular and found in more than $50 \%$ of the lobules. Many Kupffer cells were also present. It had larger total fat cell areas than the control. There was no significant portal inflammation or hepatocytes damage at aripeprazole treated rats (Figure 2). And the portal tract showed small aggregates of chronic inflammatory cells.Combined olanzapineand aripiprazole-treated rats (Figure 4) showed less prominent and less severe picture of non-alcoholic liver disease [ 3 rats] compared to olanzapine treated rats [8 rats].

In a study by Chakrakodi et al. [92], they examined the effect of aripiprazole in therapeutic dose [TD] and maximum therapeutic dose [MTD] for a period of 8 weeks on the liver histopathology of adult Sprague-Dawley rats. There was no significant portal inflammation or hepatocytes damage at TD, but at MTD, the portal tract showed small aggregates of chronic inflammatory cells.

Soliman et al. [93] compared liver histopathological changes in adult male albino rats treated with either olanzapine or aripiprazole for 14 weeks. They found histopathological changes in the liver in the form of non-alcoholic fatty liver disease in both olanzapine treated group and aripiprazole treated group. And that, these changes were more prominent and severe in olanzapine treated group than in aripiprazole treated group.

There was a trend towards an association between NASH and metabolic syndrome; in addition, patients with NAFLD with MetS were more likely to have severe steatosis and portal inflammation on liver biopsy [94]. Non-alcoholic steatohepatitis [NASH], which is recognized as a progressive form of fatty liver disease, has been documented to have the potential to progress to cirrhosis and hepatocellular carcinoma [21] [22].

\section{Conclusions and Recommendation}

Olanzapine treatment was found to be associated with risk factors of metabolic syndrome clinically and experimentally and its hepatic manifestation of nonalcoholic fatty liver disease in wister rats. These represent major challenges in the treatment of schizophrenic patients, as they reduce compliance and contribute to increased cardiovascular and hepatic morbidity among patients especially our vulnerable hepatically and metabolically Egyptian patients.

Screening for and trying to minimize risk factors [including antipsychotic medication choice and use] should be a key priority in the multidisciplinary treatment of people with schizophrenia. Schizophrenic patients on olanzapine 
therapy must be followed regularly regarding metabolic parameters, hepatic, cardiac and cerebrovascular morbidity, with urgent interference with early manifestations. It is recommended to check liver enzymes regularly for those patients kept on atypical antipsychotic drug [olanzapine]. It is also important not to ignore the signs of liver damage if one is currently taking olanzapine and signs such as jaundice, abdominal pain or discomfort should not be taken lightly while taking olanzapine.

The addition of aripiprazole in olanzapine-treated subjects with schizophrenia was well tolerated and did not result in a change of psychiatric symptoms. Improvements were observed clinically and experimentally on measurements that predict medical morbidity and mortality, including weight, fasting blood glucose, triglycerides and non-alcoholic fatty liver changes in rats.

\section{Conflicts of Interest}

The authors declare no conflicts of interest regarding the publication of this paper.

\section{References}

[1] Brown, S., Kim, M., Mitchell, C. and Inskip, H. (2010) Twenty-Five-Year Mortality of a Community Cohort with Schizophrenia. The British Journal of Psychiatry, 196, 116-121. https://doi.org/10.1192/bjp.bp.109.067512

[2] Chang, C.-K., Hayes, R.D., Perera, G., et al. (2011) Life Expectancy at Birth for People with Serious Mental Illness and Other Major Disorders from a Secondary Mental Health Care Case Register in London. PLoS ONE, 6, e19590. https://doi.org/10.1371/journal.pone.0019590

[3] Laursen, T.M., Nordentoft, M. and Mortensen, P.B. (2014) Excess Early Mortality in Schizophrenia. Annual Review of Clinical Psychology, 10, 425-448. https://doi.org/10.1146/annurev-clinpsy-032813-153657

[4] Turner, M.S. and Stewart, D.W. (2006) Review of the Evidence for the Long-Term Efficacy of Atypical Antipsychotic Agents in the Treatment of Patients with Schizophrenia and Related Psychoses. Journal of Psychopharmacology, 20, 20-37. https://doi.org/10.1177/1359786806071243

[5] Gillis, M.C. (1998) Compendium of Pharmaceuticals and Specialties. 33rd Edition, Canadian Pharmaceutical Association, Ottawa.

[6] Nasrallah, H.A. (2007) Atypical Antipsychotic-Induced Metabolic Side Effects: Insights from Receptor-Binding Profiles. Molecular Psychiatry, 13, 27-35. https://doi.org/10.1038/sj.mp.4002066

[7] Newcomer, J.W. (2005) Second-Generation (Atypical) Antipsychotics and Metabolic Effects. CNS Drugs, 19, 1-93. https://doi.org/10.2165/00023210-200519001-00001

[8] Scigliano, G. and Ronchetti, G. (2013) Antipsychotic-Induced Metabolic and Cardiovascular Side Effects in Schizophrenia: A Novel Mechanistic Hypothesis. CNS Drugs, 27, 249-257. https://doi.org/10.1007/s40263-013-0054-1

[9] Beasley, C.M., Tollefson, G.D. and Tran, P.V. (1997) Safety of Olanzapine. Journal of Clinical Psychiatry, 58, 13-17.

[10] Carlos, G.J., Antonio, S.J., Jesus, H., Breier, A., Carrasco, P.R., Saiz, C.A. and Fon- 
tova, C.E. (2000) The Safety of Olanzapine Compared with Other Antipsychotic Drugs: Results of an Observational Prospective Study in Patients with Schizophrenia (EFESO Study). Journal of Clinical Psychiatry, 61, 335-343. https://doi.org/10.4088/JCP.v61n0503

[11] Shah, R., Subhan, F., Ali, G., Ullah, I., Ahmad, N. and Fawad, K. (2016) Olanzapine Induced Biochemical and Histopathological Changes after Its Chronic Administration in Rats. Saudi Pharmaceutical Journal, 24, 698-704.

https://doi.org/10.1016/j.jsps.2015.06.006

[12] Moore, T.J., Glenmullen, J. and Mattison, D.R. (2014) Reports of Pathological Gambling, Hypersexuality, and Compulsive Shopping Associated with Dopamine Receptor Agonist Drugs. JAMA Internal Medicine, 174, 1930-1933.

https://doi.org/10.1001/jamainternmed.2014.5262

[13] Takaki, M. and Ujike, H. (2014) Aripiprazole Is Effective for Treatment of Delayed Sleep Phase Syndrome. Clinical Neuropharmacology, 37, 123-124.

https://doi.org/10.1097/WNF.0000000000000035

[14] Gami, A.S., Witt, B.J., Howard, D.E., et al. (2007) Metabolic Syndrome and Risk of Incident Cardiovascular Events and Death: A Systematic Review and Meta-Analysis of Longitudinal Studies. Journal of the American College of Cardiology, 49, 403-414. https://doi.org/10.1016/j.jacc.2006.09.032

[15] Galassi, A., Reynolds, K. and He, J. (2006) Metabolic Syndrome and Risk of Cardiovascular Disease: A Meta-Analysis. The American Journal of Medicine, 119, 812-819. https://doi.org/10.1016/j.amjmed.2006.02.031

[16] Mottillo, S., Filion, K.B., Genest, J., et al. (2010) The Metabolic Syndrome and Cardiovascular Risk: A Systematic Review and Meta-Analysis. Journal of the American College of Cardiology, 56, 1113-1132. https://doi.org/10.1016/j.jacc.2010.05.034

[17] Grundy, S.M., Cleeman, J.I. and Daniels, R.S. (2005) Diagnosis and Management of the Metabolic Syndrome: An American Heart/National Heart, Lung, and Blood Institute Scientific Statement. Circulation, 112, 2735-2752.

https://doi.org/10.1161/CIRCULATIONAHA.105.169404

[18] Alberti, K.G., Zimmet, P. and Shaw, P. (2006) The Metabolic Syndrome, a New Worldwide Definition. A Consensus Statement from the International Diabetes Federation. Diabetic Medicine, 23, 469-480. https://doi.org/10.1111/j.1464-5491.2006.01858.x

[19] Alberti, K.G., Eckel, R.H., Grundy, S.M., et al. (2009) A Joint Interim Statement of the International Diabetes Federation Task Force on Epidemiology and Prevention; National Heart, Lung, and Blood Institute; American Heart Association; World Heart Federation; International Atherosclerosis Society; and International Association for the Study of Obesity. Circulation, 120, 1640-1645.

https://doi.org/10.1161/CIRCULATIONAHA.109.192644

[20] Ballestri, S., Zona, S., Targher, G., Romagnoli, D., Baldelli, E., Nascimbeni, F., et al. (2016) Nonalcoholic Fatty Liver Disease Is Associated with an Almost Two-Fold Increased Risk of Incident Type 2 Diabetes and Metabolic Syndrome. Evidence from a Systematic Review and Meta-Analysis. Journal of Gastroenterology and Hepatology, 31, 936-944. https://doi.org/10.1111/jgh.13264

[21] Brunt, E.M., Janney, C.G., Di Bisceglie, A.M., Euschwander-Tetri, B.A. and Bacon, B.R. (1999) Non-Alcoholicsteatohepa-Titis: A Proposal for Grading and Staging the Histological Lesions. American Journal of Gastroenterology, 94, 2467-2474. https://doi.org/10.1111/j.1572-0241.1999.01377.x

[22] Giulio, M., Mara, B., Giampaolo, B., Sara, T., Elisabetta, B., Marco Arthur, J.M., 
Stefania, N., Gabriele, F. and Nazario, M. (2001) Nonalcoholic Fatty Liver Disease. A Feature of the Metabolic Syndrome. Diabetes, 50, 1844-1850.

[23] WHO (1992) 10th International Classification of Psychiatric Disorders, Research Criteria. World Health Organization, Geneva.

[24] Andreasen (1983) The Scale for the Assessment of Negative Symptoms [SANS]. The University of Iowa, Iowa City.

[25] Andreasen (1984) The Scale for the Assessment of Positive Symptoms [SAPS]. The University of Iowa, Iowa City.

[26] Center for Drug Evaluation and Research CDER, Center for Biologics Evaluation and Research CBER (2002) Estimating the Safe Starting Dose in Clinical Trials for Therapeutics in Adult Healthy Volunteers. In: Guidance for Industry and Reviewers, U.S. Food and Drug Administration, Rockville.

[27] Felici, A., Verweij, J. and Sparreboom, A. (2002) Dosing Strategies for Anticancer Drugs: The Good, the Bad and Body-Surface Area. European Journal of Cancer, 38, 1677-1684. https://doi.org/10.1016/S0959-8049(02)00151-X

[28] Shannon, R.S., Minakshi, N. and Nihal, A. (2007) Dose Translation from Animal to Human Studies Revisited. The FASEB Journal, 22, 660-670.

[29] Mortimer, P.A.M. (2007) Review: Aripiprazole for Schizophrenia-More High Quality Research Required. Evidence-Based Mental Health, 10, 14-17. https://doi.org/10.1136/ebmh.10.1.14

[30] Silver, G.A., Gutierrez-Esteinou, R. and McQuade, R.D. (2007) Aripiprazole Data on Efficacy and Associated Mortality. The British Journal of Psychiatry, 191, 86-89. https://doi.org/10.1192/bjp.191.1.86

[31] Reynolds, G.P., Zhang, Z.J. and Zheng (2002) Association of Antipsychotic DrugInduce Weight Gain with a 5-HT2C Receptor Gene Polymorphism. The Lancet, 359, 2086-2087. https://doi.org/10.1016/S0140-6736(02)08913-4

[32] Childs, C.E., Romeu-Nadal, M., Burdge, G.C. and Calder, P.C. (2010) The Polyunsaturated Fatty Acid Composition of Hepatic and Plasma Lipids Differs by Both Sex and Dietary Fat Intake in Rats. The Journal of Nutrition, 140, 245-250. https://doi.org/10.3945/jn.109.115691

[33] McNamara, R.K., Able, J., Jandacek, R., Rider, T. and Tso, P. (2009) Gender Differences in Rat Erythrocyte and Brain Docosahexaenoic Acid Composition: Role of Ovarian Hormones and Dietary Omega-3 Fatty Acid Composition. Psychoneuroendocrinology, 34, 532-539. https://doi.org/10.1016/j.psyneuen.2008.10.013

[34] Horobin, R.W. and Bancroft, J.D. (1998) Trouble-Shooting Histology Stains. Churchill Livingstone, New York.

[35] SPSS Inc. (2013) IBM SPSS Statistics for Windows. Version 22.0. IBM Corp., Armonk.

[36] Osborn, D.P.J., Levy, G., Nazareth, I., et al. (2007) Relative Risk of Cardiovascular and Cancer Mortality in People with Severe Mental Illness from the United Kingdom's General Practice Research Database. Archives of General Psychiatry, 64, 242-249. https://doi.org/10.1001/archpsyc.64.2.242

[37] Reininghaus, U., Dutta, R., Dazzan, P., et al. (2015) Mortality in Schizophrenia and Other Psychoses: A 10-Year Follow-Up of the ÆSOP First-Episode Cohort. Schizophrenia Bulletin, 41, 664-673. https://doi.org/10.1093/schbul/sbu138

[38] Walker, E.R., McGee, R.E. and Druss, B.G. (2015) Mortality in Mental Disorders and Global Disease Burden Implications: A Systematic Review and Meta-Analysis. JAMA Psychiatry, 72, 334-341. https://doi.org/10.1001/jamapsychiatry.2014.2502 
[39] Lawrence, D., Hancock, K.J. and Kisely, S. (2013) The Gap in Life Expectancy from Preventable Physical Illness in Psychiatric Patients in Western Australia: Retrospective Analysis of Population-Based Registers. BMJ, 346, f2539. https://doi.org/10.1136/bmj.f2539

[40] Saha, S., Chant, D. and McGrath, J. (2007) A Systematic Review of Mortality in Schizophrenia. Archives of General Psychiatry, 64, 1123-1131. https://doi.org/10.1001/archpsyc.64.10.1123

[41] Hoang, U., Goldacre, M.J. and Stewart, R. (2013) Avoidable Mortality in People with Schizophrenia or Bipolar Disorder in England. Acta Psychiatrica Scandinavica, 127, 195-201. https://doi.org/10.1111/acps.12045

[42] De Hert, M., Correll, C.U., Bobes, J., et al. (2011) Physical Illness in Patients with Severe Mental Disorders. I. Prevalence, Impact of Medications and Disparities in Health Care. World Psychiatry, 10, 52-77. https://doi.org/10.1002/j.2051-5545.2011.tb00014.x

[43] Mitchell, A.J. and Lord, O. (2010) Do Deficits in Cardiac Care Influence High Mortality Rates in Schizophrenia? A Systematic Review and Pooled Analysis. Journal of Psychopharmacology, 24, 69-80. https://doi.org/10.1177/1359786810382056

[44] De Hert, M., Vancampfort, D., Correll, C.U., et al. (2011) Guidelines for Screening and Monitoring of Cardiometabolic Risk in Schizophrenia: Systematic Evaluation. The British Journal of Psychiatry, 199, 99-105. https://doi.org/10.1192/bjp.bp.110.084665

[45] Mitchell, A.J., Delaffon, V., Vancampfort, D., et al. (2012) Guideline Concordant Monitoring of Metabolic Risk in People Treated with Antipsychotic Medication: Systematic Review and Meta-Analysis of Screening Practices. Psychological Medicine, 42, 125-147. https://doi.org/10.1017/S003329171100105X

[46] Gossage-Worrall, R., Holt, R.I.G., Barnard, K., et al. (2016) STEPWISE-Structured Lifestyle Education for People with Schizophrenia: A Study Protocol for a Randomized Controlled Trial. Trials, 17, Article No. 475. https://doi.org/10.1186/s13063-016-1572-1

[47] Vancampfort, D., Stubbs, B., Mitchell, A.J., De Hert, M., Wampers, M., Ward, B., Rosenbaum, S. and Correll, C.U. (2015) Risk of Metabolic Syndrome and Its Components in People with Schizophrenia and Related Psychotic Disorders, Bipolar Disorder and Major Depressive Disorder: A Systematic Review and Meta-Analysis. World Psychiatry, 14, 339-347. https://doi.org/10.1002/wps.20252

[48] Holt, R.I.G. and Peveler, R.C. (2009) Obesity, Serious Mental Illness and Antipsychotic Drugs. Diabetes, Obesity and Metabolism, 11, 665-679.

https://doi.org/10.1111/j.1463-1326.2009.01038.x

[49] Osser, D.N., Najarian, D.M. and Dufresne, R.L. (1999) Olanzapine Increases Weight and Serum Triglyceride Levels. Journal of Clinical Psychiatry, 60, 767-770. https://doi.org/10.4088/JCP.v60n1109

[50] Gupta, S., Droney, T., Al-Samarrai, S., et al. (1999) Olanzapine: Weight Gain and Therapeutic Efficacy. Journal of Clinical Psychopharmacology, 19, 273-275. https://doi.org/10.1097/00004714-199906000-00014

[51] Allison, D., Mentore, J., Heo, M., Chandler, L., Cappelleri, J., et al. (1999) Antipsychotic-Induced Weight Gain: A Comprehensive Research Synthesis. American Journal of Psychiatry, 156, 1686-1696.

[52] Alvarez-Jimenez, M., Hetrick, S.E., Gonzalez-Blanch, C., Gleeson, J.F. and McGorry, P.D. (2008) Non-Pharmacological Management of Antipsychotic-Induced Weight Gain: Systematic Review and Meta-Analysis of Randomised Controlled Trials. The 
British Journal of Psychiatry, 193, 101-107. https://doi.org/10.1192/bjp.bp.107.042853

[53] Parsons, B., Allison, D.B., Loebel, A., Williams, K., Giller, E., Romano, S. and Siu, C. (2009) Weight Effects Associated with Antipsychotics: A Comprehensive Database Analysis. Schizophrenia Research, 110, 103-110. https://doi.org/10.1016/j.schres.2008.09.025

[54] Lian, J., Huang, X.F., Pai, N. and Deng, C. (2014) Preventing Olanzapine-Induced Weight Gain Using Betahistine: A Study in a Rat Model with Chronic Olanzapine Treatment. PLoS ONE, 9, e104160. https://doi.org/10.1371/journal.pone.0104160

[55] Skrede, S., Martins, L., Berge, R.K., Steen, V.M., López, M. and Fernø, J. (2014) Olanzapine Depot Formulation in Rat: A Step Forward in Modelling Antipsychotic-Induced Metabolic Adverse Effects. International Journal of Neuropsychopharmacology, 17, 91-104. https://doi.org/10.1017/S1461145713000862

[56] Weston-Green, K., Huang, X.F., Lian, J. and Deng, C. (2012) Effects of Olanzapine on Muscarinic M3 Receptor Binding Density in the Brain Relates to Weight Gain, Plasma Insulin and Metabolic Hormone Levels. European Neuropsychopharmacology, 22, 364-373. https://doi.org/10.1016/j.euroneuro.2011.09.003

[57] Fell, M.J., Marshall, K.M., Williams, J. and Neill, J.C. (2004) Effects of the Atypicalantipsychotic Olanzapine on Reproductive Function and Weight Gain in Female Rats. Journal of Psychopharmacology, 18, 140-155. https://doi.org/10.1177/0269881104042613

[58] Cooper, G.D., Pickavance, L.C., Wilding, J.P., Halford, J.C. and Goudie, A.J. (2005) A Parametric Analysis of Olanzapine-Induced Weight Gain in Female Rats. Psychopharmacology, 181, 80-89. https://doi.org/10.1007/s00213-005-2224-4

[59] Citrome, L., Holt, R.I.G., Walker, D.J. and Hoffmann, V.P. (2011) Weight Gain and Changes in Metabolic Variables Following Olanzapine Treatment in Schizophrenia and Bipolar Disorder. Clinical Drug Investigation, 31, 455-482. https://doi.org/10.2165/11589060-000000000-00000

[60] Kahn, R.S., Fleischhacker, W.W., Boter, H., et al. (2008) Effectiveness of Antipsychotic Drugs in First-Episode Schizophrenia and Schizophreniform Disorder: An Open Randomised Clinical Trial. The Lancet, 371, 1085-1097. https://doi.org/10.1016/S0140-6736(08)60486-9

[61] Tek, C., Kucukgoncu, S., Guloksuz, S., Woods, S.W., Srihari, V.H. and Annamalai, A. (2015) Antipsychotic-Induced Weight Gain in First-Episode Psychosis Patients: A Meta-Analysis of Differential Effects of Antipsychotic Medications. Early Intervention in Psychiatry, 10, 193-202. https://doi.org/10.1111/eip.12251

[62] Davoodi, N., Kalinichev, M. and Clifton, P.G. (2008) Comparative Effects of Olanzapine and Ziprasidone on Hypophagia Induced by Enhanced Histamine Neurotransmission in the Rat. Behavioural Pharmacology, 19, 121-128.

https://doi.org/10.1097/FBP.0b013e3282f62c66

[63] Han, M., Deng, C., Burne, T.H.J., Newell, K.A. and Huang, X.F. (2008) Short- and Long-Term Effects of Antipsychotic Drug Treatment on Weight Gain and $\mathrm{H}_{1} \mathrm{Re}$ ceptor Expression. Psychoneuroendocrinology, 33, 569-580.

https://doi.org/10.1016/j.psyneuen.2008.01.018

[64] Kim, S.F., Huang, A.S., Snowman, A.M., Teuscher, C. and Snyder, S.H. (2007) Antipsychotic Drug-Induced Weight Gain Mediated by Histamine $\mathrm{H}_{1}$ Receptor-Linked Activation of Hypothalamic AMP-Kinase. Proceedings of the National Academy of Sciences of the United States of America, 104, 3456-3459. https://doi.org/10.1073/pnas.0611417104 
[65] Sejima, E., Yamauchi, A., Nishioku, T., Koga, M., Nakagama, K., et al. (2011) A Role for Hypothalamic AMP-Activated Protein Kinase in the Mediation of Hyperphagia and Weight Gain Induced by Chronic Treatment with Olanzapine in Female Rats. Cellular and Molecular Neurobiology, 31, 985-989. https://doi.org/10.1007/s10571-011-9663-8

[66] He, M., Zhang, Q., Deng, C., Wang, H., Lian, J., et al. (2014) Hypothalamic Histamine H1 Receptor-AMPK Signaling Time-Dependently Mediates Olanzapine-Induced Hyperphagia and Weight Gain in Female Rats. Psychoneuroendocrinology, 42, 153-164. https://doi.org/10.1016/j.psyneuen.2014.01.018

[67] Souza, R.P., Tiwari, A.K., Chowdhury, N.I., Ceddia, R.B., Lieberman, J.A., et al. (2012) Association Study between Variants of AMP-Activated Protein Kinase Catalytic and Regulatory Subunit Genes with Antipsychotic-Induced Weight Gain. Journal of Psychiatric Research, 46, 462-468. https://doi.org/10.1016/j.jpsychires.2012.01.010

[68] Fernø, J., Varela, L., Skrede, S., Vázquez, M.J., Nogueiras, R., et al. (2011) Olanzapine-Induced Hyperphagia and Weight Gain Associate with Orexigenic Hypothalamic Neuropeptide Signaling without Concomitant AMPK Phosphorylation. PLoS ONE, 6, e20571. https://doi.org/10.1371/journal.pone.0020571

[69] Zhang, Q., He, M., Deng, C., Wang, H., Lian, J., et al. (2014) Hypothalamic Ghrelin Signalling Mediates Olanzapine Induced Hyperphagia and Weight Gain in Female Rats. International Journal of Neuropsychopharmacology, 17, 807-818. https://doi.org/10.1017/S1461145713001697

[70] Henderson, D.C., Cagliero, E., Gray, C., et al. (2000) Clozapine, Diabetes Mellitus, Weight Gain, and Lipid Abnormalities: A Five-Year Naturalistic Study. American Journal of Psychiatry, 157, 975-981. https://doi.org/10.1176/appi.ajp.157.6.975

[71] Koro, C.E., Fedder, D.O., L'Italien, G.J., et al. (2002) An Assessment of the Independent Effects of Olanzapine and Risperidone Exposure on the Risk of Hyperlipidemia in Schizophrenic Patients. Archives of General Psychiatry, 59, 1021-1026. https://doi.org/10.1001/archpsyc.59.11.1021

[72] Atmaca, M., Kuloglu, M., Tezcan, E., et al. (2003) Weight Gain, Serum Leptin and Triglyceride Levels in Patients with Schizophrenia on Antipsychotic Treatment with Quetiapine, Olanzapine and Haloperidol. Schizophrenia Research, 60, 99-100. https://doi.org/10.1016/S0920-9964(02)00305-5

[73] Sheitman, B.B., Bird, P.M., Binz, W., et al. (1999) Olanzapine-Induced Elevation of Plasma Triglyceride Levels. American Journal of Psychiatry, 156, 1471-1472.

[74] Yan, H., Chen, J.D. and Zheng, X.Y. (2013) Potential Mechanisms of Atypical Antipsychotic-Induced Hypertriglyceridemia. Psychopharmacology, 229, 1-7. https://doi.org/10.1007/s00213-013-3193-7

[75] Lewis, G.F., Carpentier, A., Adeli, K., et al. (2002) Disordered Fat Storage and Mobilization in the Pathogenesis of Insulin Resistance and Type 2 Diabetes. Endocrine Reviews, 23, 201-229. https://doi.org/10.1210/edrv.23.2.0461

[76] Silvestee, J.S. and Prous, J. (2005) Association of Genetic Variant of Histamine H1 and Muscarinic M3 Receptors with BMI and HbA1c Values in Patients with Antipsychotic Medication. Experimental and Clinical Psychopharmacology, 27, 289-304.

[77] Correll, C.U., Robinson, D.G., Schooler, N.R., et al. (2014) Cardiometabolic Risk in First Episode Schizophrenia-Spectrum Disorder Patients: Baseline Results from the RAISE-ETP Study. JAMA Psychiatry, 71, 1350-1363. https://doi.org/10.1001/jamapsychiatry.2014.1314

[78] Meyer, J.M. and Koro, C.E. (2004) The Effects of Antipsychotic Therapy on Serum 
Lipids: A Comprehensive Review. Schizophrenia Research, 70, 1-17. https://doi.org/10.1016/j.schres.2004.01.014

[79] Newcomer, J.W., Meyer, J.M., Baker, R.A., Eudicone, J.M., Pikalov, A., Vester-Blokland, E., McQuade, R.D., Crandall, D.T., Carson, W.H., Marcus, R.N., et al. (2008) Changes in Non-High-Density Lipoprotein Cholesterol Levels and Triglyceride/High-Density Lipoprotein Cholesterol Ratios among Patients Randomized to Aripiprazole versus Olanzapine. Schizophrenia Research, 106, 300-307. https://doi.org/10.1016/j.schres.2008.09.002

[80] Buchanan, R.W., Kreyenbuhl, J., Kelly, D.L., Noel, J.M., Boggs, D.L., Fischer, B.A., Himelhoch, S., Fang, B., Peterson, E., Aquino, P.R., et al. (2010) The 2009 Schizophrenia PORT Psychopharmacological Treatment Recommendations and Summary Statements. Schizophrenia Bulletin, 36, 71-93.

https://doi.org/10.1093/schbul/sbp116

[81] Spurling, R.D., Lamberti, J.S., Olsen, D., et al. (2007) Changes in Metabolic Parameters with Switching to Aripiprazole from Another Second-Generation Antipsychotic: A Retrospective Chart Review. Journal of Clinical Psychiatry, 68, 406-409. https://doi.org/10.4088/JCP.v68n0308

[82] Greenaway, M. and Elbe, D. (2009) Focus on Aripiprazole: A Review of Its Use in Child and Adolescent Psychiatry. Canadian Academy of Child and Adolescent Psychiatry, 18, 250-260.

[83] American Diabetes Association, American Psychiatric Association, American Association of Clinical Endocrinologists, North American Association for the Study of Obesity (2004) Consensus Development Conference on Antipsychotic Drugs and Obesity and Diabetes. Diabetes Care, 27, 596-601.

[84] Sayyaparaju, K.K., Grunze, H. and Fountoulakis, K.N. (2014) When to Start Aripiprazole Therapy in Patients with Bipolar Mania. Neuropsychiatric Disease and Treatment, 10, 459-470. https://doi.org/10.2147/NDT.S40066

[85] Kessing, L.V., Thomsen, A.F., Mogensen, U.B., et al. (2010) Treatment with Antipsychotics and the Risk of Diabetes in Clinical Practice. The British Journal of Psychiatry, 197, 266-271. https://doi.org/10.1192/bjp.bp.109.076935

[86] Henderson, D.C., Fan, X., Copeland, P.M., et al. (2009) Aripiprazole Added to Overweight and Obese Olanzapine-Treated Schizophrenia Patients. Journal of Clinical Psychopharmacology, 29, 165-169. https://doi.org/10.1097/JCP.0b013e31819a8dbe

[87] Gonzalez-Heydrich, J., Raches, D., Wilens, T.E., Leichtner, A. and Mezzacappa, E. (2003) Retrospective Study of Hepatic Enzyme Elevations in Children Treated with Olanzapine, Divalproex, and Their Combination. Journal of the American Academy of Child \& Adolescent Psychiatry, 42, 1227-1233. https://doi.org/10.1097/00004583-200310000-00014

[88] Ozcanli, T., Erdogan, A., Ozdemir, S., Onen, B., Ozmen, M., Doksat, K. and Sonsuz, A. (2006) Severe Liver Enzyme Elevations after Three Years of Olanzapine Treatment: A Case Report and Review of Olanzapine Associated Hepatotoxicity. Progress in Neuro-Psychopharmacology \& Biological Psychiatry, 30, 1163-1166. https://doi.org/10.1016/j.pnpbp.2006.03.014

[89] Atasoy, N., Erdogan, A., Yalug, I., et al. (2007) A Review of Liver Function Tests during Treatment with Atypical Antipsychotic Drugs: A Chart Review Study. Progress in Neuro-Psychopharmacology \& Biological Psychiatry, 31, 1255-1260. https://doi.org/10.1016/j.pnpbp.2007.05.005

[90] Odaci, E., Bilen, H., Hacimuftuoglu, A., Keles, O.N., Can, İ. and Bilici, M. (2009) 
Long-Term Treatments with Low- and High Dose Olanzapine Change Hepatocyte Numbers in Rats. A Stereological and Histopathological Study. Archives of Medical Research, 40, 139-145. https://doi.org/10.1016/j.arcmed.2009.02.006

[91] Smith, B.W. and Adams, L.A. (2011) Non-Alcoholic Fatty Liver Disease. Critical Reviews in Clinical Laboratory Sciences, 48, 97-113.

https://doi.org/10.3109/10408363.2011.596521

[92] Shastry, C.S., Shafeeque, A.A. and Ashwathnarayana, B.J. (2013) Effect of Combination of Aripiprazole with Carbamazepine and Fluvoxamine on Liver Functions in Experimental Animals. Indian Journal of Pharmacology, 45, 121-125. https://doi.org/10.4103/0253-7613.108280

[93] Soliman, H.M., Wagih, H.M., Algaidi, S.A. and Hafiz, A.H. (2013) Histological Evaluation of the Role of Atypical Antipsychotic Drugs in Inducing Non-Alcoholic Fatty Liver Disease in Adult Male Albino Rats: Light and Electron Microscopic Study. Folia Biologica, 59, 173-180.

[94] Kanwar, P., Nelson, J.E., Yates, K., Kleiner, D.E., Unalp-Arida, A. and Kowdley, K.V. (2016) Association between Metabolic Syndrome and Liver Histology among NAFLD Patients without Diabetes. BMJ Open Gastroenterology, 3, e000114. https://doi.org/10.1136/bmjgast-2016-000114 